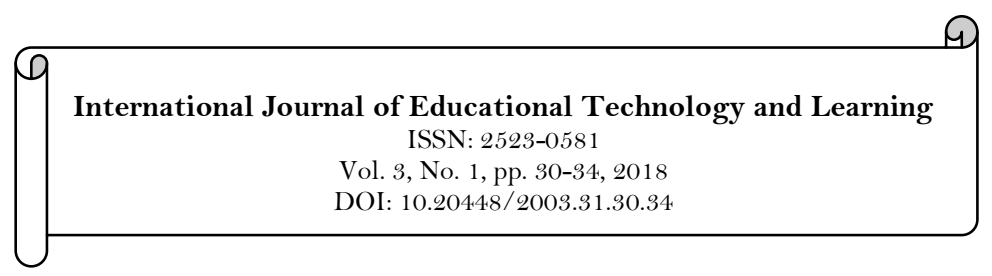

\title{
A Review on Effect of Social Media on Education in Sudan
}

\author{
Mohamed Ibrahim Alsaid Hassan ${ }^{1 *}$ \\ Piet Kommers ${ }^{2}$
}

${ }^{1}$ College of Computer Science and Technology Sudan University of Science and Technology, SUST Khartoum, Sudan. Email:mrsmohamed4.50@gmail.com

${ }^{2}$ Faculty of Behavioural Sciences, University of Twente, AE Enschede, The Netherlands.

\begin{tabular}{|c|c|}
\hline Abstract & \\
\hline $\begin{array}{l}\text { Social networking is one of the most important media outlets, whose } \\
\text { stars have risen in cyberspace, becoming a prominent communication } \\
\text { tool, particularly in students' communities. Technology integration } \\
\text { is being increasingly used in instruction to improve teaching and } \\
\text { learning. In Sudan as a developing country, the extent to which } \\
\text { educators are able to integrate social media into the curriculum is } \\
\text { limited. There is no actual practice of ICT in the learning process, } \\
\text { but use it as an additional use in the teaching process. New methods } \\
\text { must be improved to integrate that into the curriculum. In this } \\
\text { survey paper, past and recent related works are reviewed some } \\
\text { investigated to use Social media by teachers in promoting the } \\
\text { educational process. }\end{array}$ & $\begin{array}{l}\text { Keywords: } \\
\text { Social media SM } \\
\text { Learning } \\
\text { Teaching } \\
\text { Technology integration. } \\
\text { ICT in learning. } \\
\text { Licensed: } \\
\text { This work is licensed under a } \\
\text { Creative Commons Attribution } \\
\text { 4.0 License. } \\
\text { Publisher: } \\
\text { Scientific Publishing Institute }\end{array}$ \\
\hline
\end{tabular}

\section{Introduction}

Information and communication technologies (ICT) became the backbone for the current and future services. In the last decade, major changes in methods and operations of everyday life were witnessed. ICT become the actual measure for progress and success of countries at all levels. Social media is a tool used for social interaction (Cheong \& Cheong, 2011). Social media consists of popular Web sites and it emphasizes the communication and the exchange of opinion and ideas. Some sites have been more popular than others. In Sudan people use face-book and twitter more than other social network. The social media plays an important role in all aspect of life. Social network websites grab attention of the students and diverts it towards noneducational and unproductive actions including useless chatting, that can to be an impediment to the success of Web 2.0 in higher education (Khan, 2012; Pervaiz, 2016; Yeboah \& Ewur, 2014). In contrast, Many surveys have been investigated by many researchers during the previous years, the existence of credible evidence that social media can be used to support and enhance the learning process, engage learners and network for learning activities (Al-Rahmi \& Zeki, 2017; Balakrishnan \& Gan, 2016; Greenhow \& Askari, 2017; Taiwo \& Adesegun, 2018).

It should be noted that you cannot place restrictions on the use of social media or turn off chat across social networking sites. This has led to a rise in questions about the impact of SMNs on academic performance and the possibility of using it as an effective teaching tool. In this article, the researchers will examine some of the important issues related to the social media network, and how it affects the students and teachers in the educational process.

\section{Social Media for Learning}

Social network site SNSs are increasingly being used for educational purposes. SNSs have a great role in online student support and also in enhancing the quality of learning, as students can interact, communicate, and share their knowledge and experience with other friends or colleagues in interactive social dialogue. There are studies for psychologists in how to stimulate social systems in ways that support the related communication processes that allow individuals to interact with others, autonomously externalize their knowledge, and contribute to collective idea improvement (Kimmerle, Moskaliuk, Oeberst, \& Cress, 2015). The students depend on social media in their daily lives for leisure and social connections. Educational uses by teachers for classroom teaching and learning are sporadic, while uses by students on their own for learning purposes seems to be abundant but also incidental and informal (Greenhow \& Lewin, 2016). Frequent usage 
of enterprise social networking systems (ESNS) usage can stimulate knowledge creation and knowledge sharing and eventually help in the long-term learning outcomes of the organizations (Qi \& Chau, 2018). Of the 22 studies, $77 \%$ reported very favorable views of college students on instructional adaptations to SM technologies. No studies found outright rejection of modern SM platforms for instructional use by today's undergraduate and graduate-level students (Piotrowski, 2015).

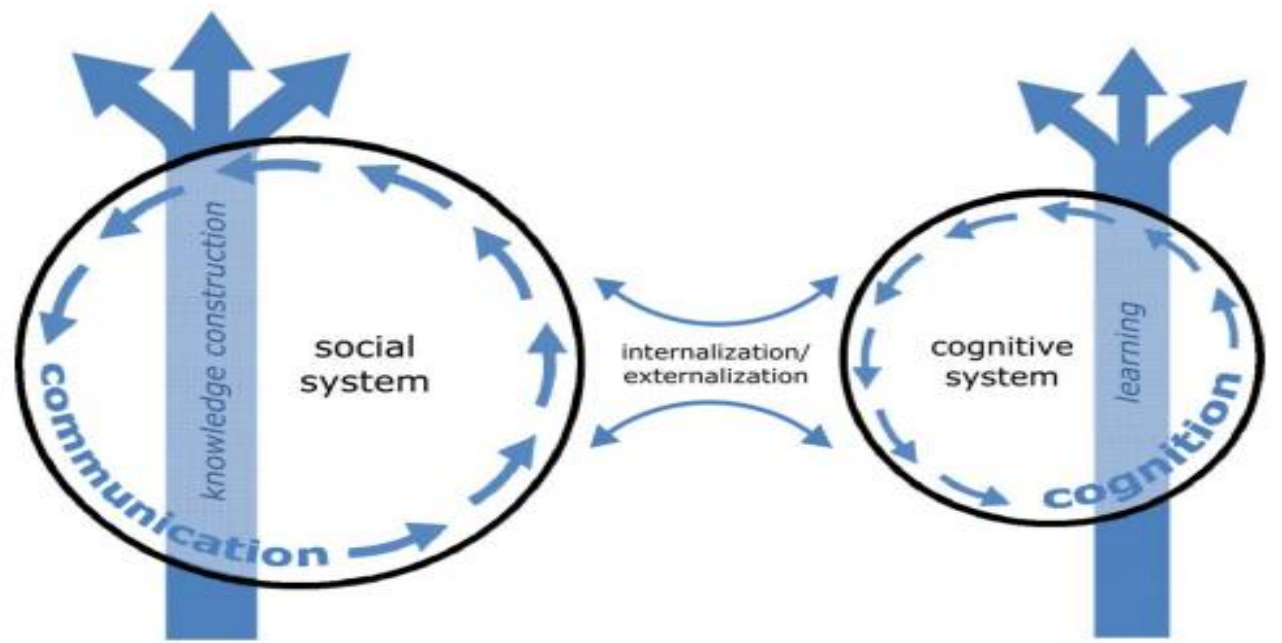

Figure-1. The dynamic processes of learning and knowledge construction. Source: This figure is designed by (Kimmerle, et al 2015).

\section{Integrating Social Media into the Education Curriculum}

Over the last 25 years, educational technology (Ed-tech)1 in Higher Education (HE) has been promoted as having the potential to transform teaching and learning. Research indicates those teachers' conceptions of and approaches to teaching with technology are central for the successful implementation of educational technologies in higher education. However, focusing on the professional development activities especially on novice/early career academics as they enter the profession is likely to lead to a more lasting and progressive impact on the field. By supporting HE teachers in the task of changing their conceptions of teaching and learning, a more effective use of Ed-tech can be achieved and the lack of educational gains made since the digital revolution became a part of HE may be remedied (England, Olofsson, \& Price, 2017). That college students are integrating social media in their academic experience both formally and informally. Furthermore, college faculties are increasingly using social media to support teaching and learning activities (Dabbagh \& Kitsantas, 2012; Hickerson \& Kothari, 2017) Argued that if students and faculties model good values and practice their interactions with each other, they will be more likely to exhibit these traits in their social media after the class concludes (Hickerson \& Kothari, 2017). Social media provides teachers with the existing of new opportunities to connect with students in a manner that continues to provoke thought and discussion outside of the classroom setting. The use of social media encourages students to interact with one another and may increase engagement and interest in the course content. Though several studies outlined in this article called for further research. In many cases the benefits of using social media appears to outweigh the limitations of it (Abe \& Jordan, 2013).

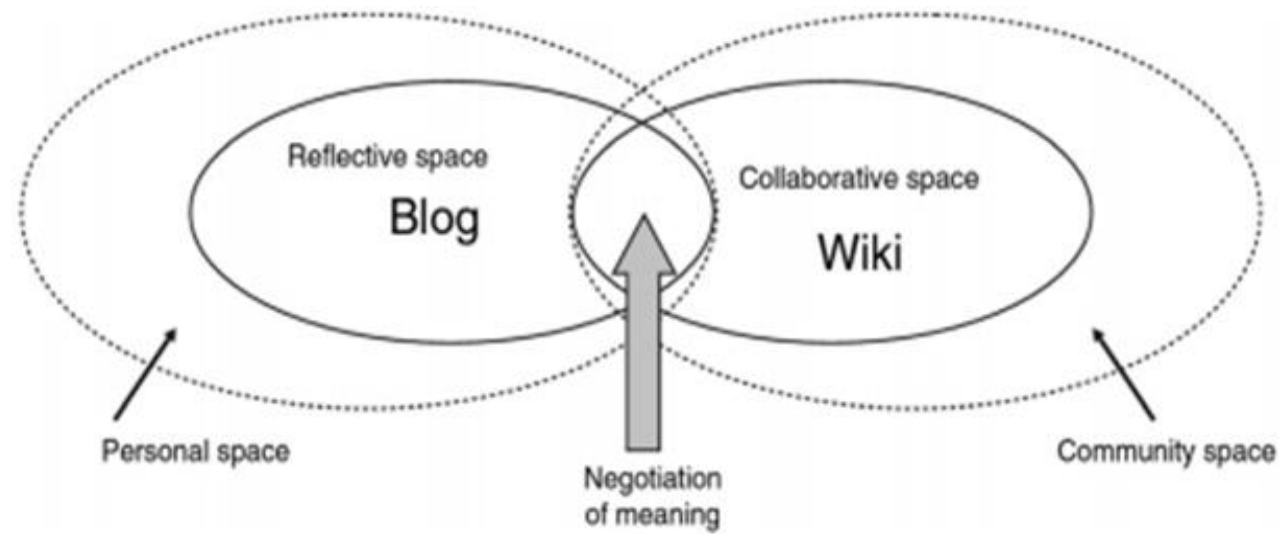

Figure-2. Depiction of social media in higher education

This picture designed by (Chawinga, 2017). 


\section{Related Works}

This section reviews recent and past related research on social media networks. We have to mention that the effect of SNSs on learning is examined, and how it affects the students and teachers in the educational process.

The social development factor has the highest influence in the social networking, Also, the Internet affect study and work behavior negatively. Since this was a cross-sectional study, it is not possible to determine whether a student's spends less time on social networks because she/he experienced its negative effects (Balakrishnan \& Gan, 2016).

The author spotted the lights on the negative effects of social networking sites are considerable and abundant and it is crucial to proceed with caution and curb the excessive usage and dependence on social networking sites. Although there are many serious negative effects of social networking, but one cannot categorically conclude that. The social networking should be removed from our lives. Social networks offer numerous benefits and its negative impacts can be brought under control with careful planning and management (Sarkar, Agarwal, Ghosh, \& Nath, 2015).

In 2016 a survey was administered at a large public university located in the Mid-Atlantic region of the United States. Sixteen instructors from the College of Education were asked to forward an email to their students asking them to complete an online survey regarding their use of social networking. The majority of the participants $(56 \%)$ reported spending less than one-hour social networking per day while $34 \%$ of the participants reported to spend up to five hours social networking per day. It is also reported that $67 \%$ of internet users in the U.S. whose age ranges between 18 and 29 use social networking sites (SNS) such as Facebook, Twitter, Pinterest, Instagram, and Tumblr, while only $44.1 \%$ of faculty members in higher education use social media in their teaching with a higher percentage in the Humanities and Arts disciplines. Additionally, research also suggests that college students whose age ranges between 18 and 34 are using SNSs for long hours and that the adoption of mobile devices and mobile applications is a driving force for the increase in social networking and social media use. Data showed that social networking was helpful for communication; information gathering and that it positively influenced their academic work. However, students also reported that social networking had a negative impact on their social interactions, emotional health, and work completion (Kitsantas, Dabbagh, Chirinos, \& Fake, 2016).

This paper investigated the questions about the impact of online social network OSN on academic performance and the possibility of using it as an effective teaching tool. Survey results were analysed using structural equation modelling (SEM). The results revealed a statistically significant negative relationship between time spent by students on OSN and their academic performance. Further, attention span was found to be highly correlated with characteristics that predict or influence student behaviour, such as their perceptions about society's view of social networking, their likes and dislikes of OSN, ease of use of OSN, etc. Conclusion, OSN could be viewed as a valuable pedagogical technology. Given the lack of credible evidence that students are willing to use OSN for academic purposes and the existence of credible evidence that increasing amounts of time spent on OSN negatively affects academic performance, faculty attempts to include OSN are rationally un-founded. Therefore, there is a need for further investigation into the types of OSN exercises and applications that enhance learning as well as the types of courses for which such exercises and applications would be most appropriate (Paul, Baker, \& Cochran, 2012).

In this paper, we start working on using social networks to enhance teaching and learning experiences in higher learning institutions. Book2 $U$ was tested by the students and teacherswith Computer Science background, and hence they may be very adept at navigating and using Book2U. This was proven as the majority of them stated that Book2 $U$ was easy to use. It would be interesting to explore if students and lecturers who lack computer skill feel the same way about Book2U (Balakrishnan, 2014).

This study investigated the impact of teacher design teams as a professional development arrangement for developing technology integration knowledge and skills among in-service science teachers. Focus group discussion and reflection questionnaire data were used to assess teachers' experience of working in design teams at the end of the professional development arrangement. Findings showed an increase in teachers' technology integration knowledge and skills between pre and post-measurements. Collaboration in design teams had the potential for teachers to share knowledge, skills, experience and challenges related to technology-enhanced teaching. However, the findings presented in this study are based on one school with a specific technology infrastructure. Other schools might have a different technology infrastructure or different possibilities for working in design teams (Kafyulilo, Fisser, \& Voogt, 2016).

In this study, the Facebook group was used as a learning management system (LMS) in two courses for putting up announcements, sharing resources, organizing weekly tutorials and conducting online discussions at a teacher education institute in Singapore. This study explores using the Facebook group as an LMS and the students' perceptions of using it in their courses. Results showed that students were basically satisfied with the affordances of Facebook as the fundamental functions of an LMS could be easily implemented in the Facebook group, however, has certain constraints. It does not support other format files to be uploaded directly, and the discussion is not organized in a meaningful structure. In addition, the strong social connectivity of Facebook is a double-edged sword. It enables students to easily communicate and interact with 
peers and the teacher. However, it fails to provide a safe environment as students' perceived privacy is decreased. For effective use of Facebook in learning, many other factors like sound instructional design, positive teacher attitude and strong technical support are crucial, without which the potential will hardly be realized (Wang, Woo, Quek, Yang, \& Liu, 2012).

In 2017, a researcher conducted a study about how the use of social media facilitates in teaching and learning. This study incorporated Twitter and blogs into two undergraduate courses offered in the Department of Library and Information Science at Mzuzu University which is a public university in Malawi. Data were collected in two ways: first, analysis of blog and Twitter posts by students and second, a questionnaire was sent to 64 students to find out their perception towards the use of blogs and Twitter in a classroom environment. Results suggest that if appropriately deployed, Twitter and blogs are catalysts for the much hyped learner-centred approach to teaching because using these technologies, it emerged that students shared and discussed course materials, posted their course reflections and interacted amongst themselves and with their teachers24/7. It is clear from the findings that Twitter was hailed mainly for its timeliness i.e. students could receive instant messages on their mobile phones as attested by the following comment by one respondent: "Mostly, feedback was instant, as at least some colleagues were always online including the lecturer". The fact that Twitter has a limit of 140 characters; it required students to think critically so as to communicate their point within such a limited number of words or characters (Chawinga, 2017).

\section{Summary}

Using social media to stay in touch with the other communities could have strong payoffs in terms of internships and education, and other opportunities. Many studies relied on soliciting mere views from students and teachers about their intentions to use or not to use social media to promote the educational process. Using social media in teaching students by some instructions will have positive outcomes in learning. However, higher education institutions are still primarily relying on traditional platforms such as course and learning management systems (CMS/LMS) that do not capitalize on the pedagogical affordances of social media, for example allowing learners to manage and maintain a learning space that facilitates their own learning activities and connections to peers and social networks across time and place (Dabbagh \& Kitsantas, 2012). One of the factors that stymies the adoption of social media in higher education is that the responsibility to use these technologies is left to a teacherswith little or no interest from a university level should investigate university policies that are deliberately put in place to foster the take up and use of social media in formal learning contexts (Chawinga, 2017).

\section{References}

Abe, P., \& Jordan, N. A. (2013). Integrating social media into the classroom curriculum. About Campus, 18(1), 16-20.

Al-Rahmi, W. M., \& Zeki, A. M. (2017). A model of using social media for collaborative learning to enhance learners' performance on learning. Journal of King Saud University-Computer and Information Sciences, 29(4), 526-535.

Balakrishnan, V. (2014). Using social networks to enhance teaching and learning experiences in higher learning institutions. Innovations in Education and Teaching International, 51(6), 595-606.

Balakrishnan, V., \& Gan, C. L. (2016). Students' learning styles and their effects on the use of social media technology for learning. Telematics and Informatics, 33(3), 808-821.

Chawinga, W. D. (2017). Taking social media to a university classroom: Teaching and learning using Twitter and blogs. International Journal of Educational Technology in Higher Education, 14(1), 1-19.

Cheong, F., \& Cheong, C. (2011). Social media data mining: A social network analysis of tweets during the $2010-2011$ Australian floods. PACIS, 11, 46-46.

Dabbagh, N., \& Kitsantas, A. (2012). Personal Learning Environments, social media, and self-regulated learning: A natural formula for connecting formal and informal learning. Internet and Higher Education, 15(1), 3-8.

England, C., Olofsson, A. D., \& Price, L. (2017). Teaching with technology in higher education: understanding conceptual change and development in practice. Higher Education Research Eं Development, 36(1), 73-87.

Greenhow, C., \& Askari, E. (2017). Learning and teaching with social network sites: A decade of research in K-12 related education. Education and Information Technologies, 22(2), 623-645.

Greenhow, C., \& Lewin, C. (2016). Social media and education: Reconceptualising the boundaries of formal and informal learning. Learning, Media and Technology, 41(1), 6-30.

Hickerson, A., \& Kothari, A. (2017). Learning in public: Faculty and student opinions about social media in the classroom. Journalism \& Mass Communication Educator, 72(4), 397-409.

Kafyulilo, A., Fisser, P., \& Voogt, J. (2016). Teacher design in teams as a professional development arrangement for developing technology integration knowledge and skills of science teachers in Tanzania. Education and Information Technologies, 21(2), 301-318.

Khan, S. (2012). Impact of social networking websites on students. Abasyn Journal of Social Sciences, 5(2), 56-77.

Kimmerle, J., Moskaliuk, J., Oeberst, A., \& Cress, U. (2015). Learning and collective knowledge construction with social media: A process-oriented perspective. Educational Psychologist, 50(2), 120-137.

Kitsantas, A., Dabbagh, N., Chirinos, D. S., \& Fake, H. (2016). College students' perceptions of positive and negative effects of social networking. In Social Networking and Education (pp. 225-238). Springer: Cham.

Paul, J. A., Baker, H. M., \& Cochran, J. D. (2012). Effect of online social networking on student academic performance. Computers in Human Behaviour, 28(6), $2117-2127$. 
Pervaiz, S. (2016). The advantages and risks of using social networking in higher education in Pakistan. In Social Networking and Education (pp. 83-97). Springer: Cham.

Piotrowski, C. (2015). Academic applications of social media: A review of peer-review research in higher education. Psychology \& Education, 52(3-4), 15-22.

Qi, C., \& Chau, P. Y. K. (2018). Will enterprise social networking systems promote knowledge management and organizational learning? An empirical study. Journal of Organizational Computing and Electronic Commerce, 28(1), $31-57$.

Sarkar, A., Agarwal, S., Ghosh, A., \& Nath, A. (2015). Impacts of social networks: A comprehensive study on positive and negative effects on different age groups in a society. International Journal, 3(5), 177-190.

Taiwo, Y. H., \& Adesegun, O. O. (2018). Lecturers'readiness towards the integration of social media for teaching in a Nigerian university. International Journal for Innovative Technology Integration in Education, 1(1), 57-64.

Wang, Q., Woo, H. L., Quek, C. L., Yang, Y., \& Liu, M. (2012). Using the Facebook group as a learning management system: An exploratory study. British Journal of Educational Technology, 43(3), 428-438.

Yeboah, J., \& Ewur, G. D. (2014). The impact of WhatsApp messenger usage on students performance in tertiary institutions in Ghana. Journal of Education and Practice, 5(6), 157-164. 